\title{
Depression in Cancer Patients: Magnitude of Problem and Factors Responsible
}

\begin{abstract}
Context: Cancer patients usually have various psychological complications, depression being the most common among them. Depression poses difficulties in continuing the prescribed treatment within the scheduled time frame, ultimately affecting the outcome. Aims: The aims of this study were to determine the magnitude of depression and various factors associated with it, to initiate the timely intervention. Subjects and Materials: Brief Edinburgh Depression Scale was used to measure depression in 203 cancer patients who received chemotherapy at Department of Radiotherapy, SMS Medical College, Jaipur; in August 2017, were above 18 years of age, and could read, understand, and write. Association of depression with various factors such as age, gender, education and occupation details, income, marital status, history of other comorbid disease, type and site of cancer, presence of metastases, number of chemotherapy cycles going on, and source of cost of therapy, was also computed. Results: Of 203 patients, depression was present in 130 (64\%) patients. Statistically significant association of depression was found with both extremes of the age $(P=0.04)$, paid treatment $(P=0.03)$, and $<4$ chemotherapy cycles $(P=0.04)$. No significant association was seen between depression and gender, occupation, performance status, site of cancer, presence of coexisting disease, and metastases. Conclusions: The magnitude of depression was high (present in $64 \%$ of patients) which often gets unnoticed. Depression should routinely be screened among cancer patients receiving chemotherapy and patients found to have depression should be referred to a psychiatrist for timely management.
\end{abstract}

Keywords: Brief Edinburgh Depression Scale, cancer, chemotherapy, depression

\section{Introduction}

The $10^{\text {th }}$ revision of the International Statistical Classification of Diseases and Related Health Problems defines depressive episodes as suffering from lowering of mood, reduction of energy, and decrease in activity. ${ }^{[1]}$ Depending on the number and severity of the symptoms, a depressive episode may be specified as mild, moderate, or severe. Usually, the capacity for enjoyment, interest, and concentration is reduced, and marked tiredness after even minimum effort is common. Sleep is usually disturbed and appetite diminished. Self-esteem and self-confidence are almost always reduced and even in the mild form, some ideas of guilt or worthlessness are often present.

Cancer patients usually have various psychological complications in the form of adjustment disorder, depressed mood, anxiety, impoverished life satisfaction,

This is an open access journal, and articles are distributed under the terms of the Creative Commons Attribution-NonCommercial-ShareAlike 4.0 License, which allows others to remix, tweak, and build upon the work non-commercially, as long as appropriate credit is given and the new creations are licensed under the identical terms.

For reprints contact: reprints@medknow.com or loss of self-esteem, with depression being the most common among them. ${ }^{[2]}$ Depression begins as soon as the diagnosis of cancer is confirmed. The causes of depression are many, such as various myths and misconception about cancer treatment and outcome, battery of investigations patient is required to undergo, multiple referrals, repeated hospitalization, concern about loss of organ in case of surgery or side effects in case of chemo/radiotherapy, and long course of treatment. Depression not only causes great suffering to the patient but also put psychological and financial burden on the family. Katon has described a bidirectional relationship between depression and chronic medical disorders. ${ }^{[3]}$ Comorbid depression is associated with increased medical symptom burden, functional impairment, medical costs, poor adherence to self-care regimens, and increased risk of morbidity and mortality in patients with chronic medical disorders; ultimately worsening the course of medical disorders.

How to cite this article: Rastogi K, Rakesh A,
Bairwa SC, Bhaskar S, Gupta S, Sharma S, et al.
Depression in cancer patients: Magnitude of problem
and factors responsible. Indian J Med Paediatr Oncol
2019;40:542-6.

\section{Kartick Rastogi ${ }^{1}$, Amrita Rakesh², Subhash Chand Bairwa1, Sandeep Bhaskar ${ }^{1}$, Shivani Gupta ${ }^{1}$, Shantanu Sharma ${ }^{1}$, Sandeep Jain ${ }^{1}$}

${ }^{1}$ Department of Radiotherapy, SMS Medical College and Attached Group of Hospitals, ${ }^{2}$ Department of Radiation Oncology, BMCHRC, Jaipur, Rajasthan, India

Submitted: 01-May-2018 Accepted in Revised Form: 21-Jun-2018

Published: 17-Feb-2020

Address for correspondence: Dr. Kartick Rastogi,

Department of Radiotherapy, SMS Hospital, Jaipur,

Rajasthan, India.

E-mail: atc9atc9@gmail.com

Access this article online

Website: www.ijmpo.org

DOI: 10.4103/ijmpo.ijmpo_99_18 Quick Response Code:

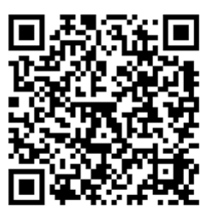


Depression in cancer patients may pose several difficulties in continuing the prescribed treatment within the scheduled time frame, which may ultimately affect the outcome, leading to increased morbidity and mortality. Determining the magnitude of depression and various factors associated with it, is of utmost importance to initiate the timely intervention, which may be either counseling, psychotherapy, antidepressant medication, or even alternative/complementary medicine such as yoga and meditation. There is also a need to know the point of appropriate referral of such patients to a psychiatrist. As far as Indian data are concerned, very limited literature is available tackling with this situation, which necessitated the present study to be carried out.

\section{Subjects and Methods}

The present study was a cross-sectional descriptive type of the study conducted at the Day Care Center of the Department of Radiotherapy, SMS Medical College and attached group of hospitals, Jaipur, Rajasthan, India, during August 2017. The objectives of the present study were to determine the magnitude of depression in cancer patients receiving chemotherapy and various factors associated with it. Among the cancer patients who received chemotherapy during the study period, those who were above 18 years of age, were receiving chemotherapy for the first time and gave written informed consent for participating in the study were included in the study. Such patients were interviewed clinically. They were given a two-page questionnaire: the first page consisted of basic information, such as name, age, gender, contact details, education and occupation details, history of other comorbid disease, type and site of cancer, presence of metastases, number of chemotherapy cycle going on, and finance of cost of therapy. The inclusion of items in the questionnaire was based on the available literature as predictors for depression (cited in discussion part). In the end was the consent regarding the use of the information provided for research purpose, to be signed by the subject.

The second page consisted of the Brief Edinburgh Depression Scale (BEDS) to screen and measure depression. Although some methods are available for measuring depression, there is no common consensus regarding the superiority of one over another. We used BEDS as it is an easily understandable method to measure depression. BEDS is a 6-item inventory rated on a 4-point Likert-type scale, developed by Lloyd-Williams, Shiels, and Dowrick, to briefly and accurately measure depression exclusively in patients with advanced stages of cancer. ${ }^{[4]}$ The six objective items mainly focus on the subjective feelings of worth and sadness. Each item has a four-point response score ranging from 0 to 3 ; hence, a minimum score of 0 and a maximum score of 18 can be obtained. A score of 6 or above is indicative of depression, giving a sensitivity of $72 \%$ and specificity of $83 \%$ with a positive predictive value of $65.1 \%$ and negative predictive value of $87.1 \%$. The questions and the options for each question were explained to the patients in their language and they were asked to suggest the most accurate answer on the basis of how they felt in the previous month.

A total of 203 patients were found eligible for analysis. All data were entered in Microsoft Excel sheet for windows. The presence of depression was evaluated on the basis of BEDS score, with a score of 6 or above indicating depression. To identify predictors of depression, hazard ratio, 95\% confidence interval, and $P$-value were calculated with the XLSTAT software version 2017 for Windows (Addinsoft, NY, USA) using logistic regression analysis, considering the presence of depression as 1 and absence as 0 . In all calculations, the significance level was taken as 0.05 .

\section{Results}

The baseline patient and tumor characteristics are shown in Table 1. About two-third of the patients were male, above 50 years of age, paid for the treatment, and receiving $<4^{\text {th }}$ cycle of chemotherapy. About half of the patients were doing private (unsecure) job with the Eastern Cooperative Oncology Group Performance Status (ECOG PS) 0-2. Less than quarter of the patients had other comorbid disease or metastases. The most common primary was the head and neck, followed by the gastrointestinal tumor. Of 203 patients, depression was present in $130(64 \%)$ patients. The statistical analysis of various parameters associated with depression is shown in Table 2. Statistically significant association of depression was found with age (being higher with both extremes of ages), finance of treatment (being higher with paid versus free treatment), and number of chemotherapy cycles (being higher with less than the fourth cycle of chemotherapy). No significant association was seen between depression and gender, occupation, ECOG PS, site of cancer, presence of coexisting disease, and metastases.

\section{Discussion}

Various studies have used different scales to measure the magnitude of depression in cancer patients. Zielińska-Wieczkowska and Betłakowski analyzed depression in cancer patients undergoing chemotherapy using Zung Self-rating Depression Scale and concluded that depression was more in women, people with vocational education, and patients unable to continue working. ${ }^{[5]}$ Lloyd-Williams investigated 100 patients with advanced metastatic disease from North West England regarding suffering and their psychological, physical, social, and spiritual well-being, using the BEDS, Edmonton Symptom Assessment Scale (ESAS), and Functional Assessment of Chronic Illness Therapy-Spiritual well-being questionnaire and found no significant difference at any time point in scores on suffering measure. ${ }^{[6]}$ Decat, 


\begin{tabular}{|c|c|}
\hline \multicolumn{2}{|c|}{$\begin{array}{l}\text { Table 1: Baseline patient, tumor, and treatment } \\
\text { characteristics of entire cohort }\end{array}$} \\
\hline Parameters & $n(\%)$ \\
\hline \multicolumn{2}{|l|}{ Age (years) } \\
\hline$<30$ & $8(3.9)$ \\
\hline $30-50$ & $72(35.5)$ \\
\hline$>50$ & $123(60.6)$ \\
\hline \multicolumn{2}{|l|}{ Gender } \\
\hline Male & $141(69.5)$ \\
\hline Female & $62(30.5)$ \\
\hline \multicolumn{2}{|l|}{ Occupation } \\
\hline Unemployed/dependent & $82(40.4)$ \\
\hline Unsecure job & $96(47.3)$ \\
\hline Secure job & $25(12.3)$ \\
\hline \multicolumn{2}{|l|}{ Finance of treatment } \\
\hline Paid & $141(69.5)$ \\
\hline Free & $62(30.5)$ \\
\hline \multicolumn{2}{|l|}{ ECOG PS } \\
\hline $0-2$ & $110(54.2)$ \\
\hline $3-4$ & $93(45.8)$ \\
\hline \multicolumn{2}{|l|}{ Site of cancer } \\
\hline Head and neck & $63(31)$ \\
\hline Breast & $38(18.7)$ \\
\hline Genitourinary & $20(9.9)$ \\
\hline Gastrointestinal & $46(22.7)$ \\
\hline Lung & $22(10.8)$ \\
\hline Others & $14(6.9)$ \\
\hline \multicolumn{2}{|l|}{ Coexisting disease } \\
\hline Present & $42(20.7)$ \\
\hline Absent & $161(79.3)$ \\
\hline \multicolumn{2}{|l|}{ Metastases } \\
\hline Present & $23(11.3)$ \\
\hline Absent & $180(88.7)$ \\
\hline \multicolumn{2}{|l|}{ Chemotherapy cycle } \\
\hline$<4$ & $123(60.5)$ \\
\hline$\geq 4$ & $80(39.5)$ \\
\hline
\end{tabular}

ECOG PS - Eastern Cooperative Oncology Group Performance Status

de Araujo, and Stiles J measured distress in 100 patients at three points during chemotherapy: beginning, middle, and the last day of therapy in Brazil using the distress thermometer and the Hospital Anxiety and Depression Scale (HADS) ${ }^{[7]}$ The percentages of distress, anxiety, and depression, respectively, in the beginning, in the middle, and on the last day were $82 \%, 78 \%$, and $55 \% ; 36.4 \%$, $25 \%$, and $25.3 \%$; and $18.2 \%, 14.3 \%$, and $14.3 \%$.

In the present study, depression was present in $64 \%$ of patients. Various studies have described different incidence of depression in cancer patients, using different scales of measurement. Burgess et al. did an observational cohort study in London on 222 women with early breast cancer and concluded that nearly $50 \%$ of the women with early breast cancer had depression, anxiety, or both in the year after diagnosis, $25 \%$ in the $2^{\text {nd }}, 3^{\text {rd }}$, and $4^{\text {th }}$ years and $15 \%$ in the $5^{\text {th }}$ year ${ }^{[8]}$ Point prevalence was $33 \%$ at diagnosis, falling to $15 \%$ after 1 year. Nearly, $45 \%$ of those with recurrence experienced depression, anxiety, or both within 3 months of the diagnosis. Pandey et al. evaluated the effect of chemotherapy on distress, anxiety, and depression in 117 patients using distress inventory for cancer and HADS. ${ }^{[9]}$ The mean distress score was $24 ; 15.38 \%$ of patients were found to have anxiety, while $16.23 \%$ patients had depression. Walker et al. systematically reviewed published studies to obtain the best estimate of the prevalence of depression in clinically meaningful subgroups of cancer patients and found the estimated prevalence of depression in the defined subgroups to be $5 \%-16 \%$ in outpatients, $4 \%-14 \%$ in inpatients, $4 \%-11 \%$ in mixed outpatient and inpatient samples, and $7 \%-49 \%$ in palliative care. ${ }^{[10]}$

In the present study, depression was significantly associated with both extremes of age $(P=0.04)$, paid treatment $(P=0.03)$, and less than fourth cycles of chemotherapy $(P=0.04)$. Maneeton et al. studied the prevalence of depression among 108 Thai patients with cancer, using the Patient Health Questionnaire - 9; in addition, suicidal risk was assessed using the Mini-International Neuropsychiatric Interview (MINI). ${ }^{[1]}$ They found that $29.6 \%$ of patients were diagnosed with a depressive disorder (mild, 14.8\%; moderate, 5.6\%; and severe, 9.3\%). According to the MINI, $28.1 \%$ of these depressed cancer patients had a moderate-to-severe level of suicidal risk. The increased risk of depression was significantly associated with increased pain score, lower number of cancer treatments $(<2$ methods), increased educational duration ( $>13$ years), increased age ( $>50$ years old), and female sex. Akechi et al. investigated clinical indicators of depression among 211 randomly selected ambulatory patients with cancer who were receiving chemotherapy using the HADS, the European Organization for Research and Treatment of Cancer QLQ-C 30 and an ad hoc questionnaire regarding several additional common chemotherapy-related symptoms. ${ }^{[12]}$ Depression was present in $13.7 \%$ of patients. The presence of clinical depression was significantly associated with the presence of pain, sleep disturbances, loss of appetite, nausea, and fatigue. Multivariate logistic regression analysis indicated that a lower education level and the presence of pain were significantly associated with clinical depression.

The BEDS score used in the present study has been used in some studies. Rhondali et al. evaluated depression in 146 cancer patients using the BEDS and identified associated symptoms of cancer using the ESAS. ${ }^{[13]}$ The prevalence of probable depression was $29 \%$. Probable depression was associated with increased fatigue $(P=0.008)$, depression $(P<0.001)$, anxiety $(P<0.001)$, shortness of breath $(P=0.01)$, and decreased feeling of well-being $(P<0.001)$. Among patients with probable depression, $98 \%$ of patients were not using antidepressants. 


\begin{tabular}{|c|c|c|c|c|}
\hline Parameters & Entire cohort, $n(\%)$ & Depression, $n(\%)$ & Odds ratio $(95 \% \mathrm{CI})$ & $P$ \\
\hline \multicolumn{5}{|l|}{ Age (years) } \\
\hline$<30$ & $8(3.9)$ & $5(62.5)$ & $1.491(0.331-6.172)$ & 0.04 \\
\hline $30-50$ & $72(35.5)$ & $38(52.8)$ & 1 & \\
\hline$>50$ & $123(60.6)$ & $87(70.7)$ & $2.162(1.182-3.956)$ & \\
\hline \multicolumn{5}{|l|}{ Gender } \\
\hline Male & $141(69.5)$ & $86(60.9)$ & 1 & 0.23 \\
\hline Female & $62(30.5)$ & $44(70.9)$ & $1.563(0.821-2.978)$ & \\
\hline \multicolumn{5}{|l|}{ Occupation } \\
\hline Unemployed/dependent & $82(40.4)$ & $53(64.6)$ & $1.407(0.526-3.762)$ & 0.61 \\
\hline Unsecure job & $96(47.3)$ & $59(61.5)$ & 1 & \\
\hline Secure job & $25(12.3)$ & $18(72)$ & $1.608(0.473-2.873)$ & \\
\hline \multicolumn{5}{|l|}{ Finance of treatment } \\
\hline Paid & $141(69.5)$ & $83(58.8)$ & $2.190(1.119-4.284)$ & 0.03 \\
\hline Free & $62(30.5)$ & $47(75.8)$ & 1 & \\
\hline \multicolumn{5}{|l|}{ ECOG PS } \\
\hline $0-2$ & $110(54.2)$ & $76(69.1)$ & $1.614(0.906-2.875)$ & 0.14 \\
\hline $3-4$ & $93(45.8)$ & $54(58.1)$ & 1 & \\
\hline \multicolumn{5}{|l|}{ Site of cancer } \\
\hline Head and neck & $63(31)$ & $42(66.7)$ & $0.860(0.240-3.078)$ & 1.0 \\
\hline Breast & $38(18.7)$ & $25(65.8)$ & $0.867(0.226-3.331)$ & \\
\hline Genitourinary & $20(9.9)$ & $14(70)$ & 1 & \\
\hline Gastrointestinal & $46(22.7)$ & $27(58.7)$ & $0.622(0.169-2.288)$ & \\
\hline Lung & $22(10.8)$ & $12(54.5)$ & $0.578(0.137-2.433)$ & \\
\hline Others & $14(6.9)$ & $10(71.4)$ & $1.200(0.257-5.593)$ & \\
\hline \multicolumn{5}{|l|}{ Coexisting disease } \\
\hline Present & $42(20.7)$ & $26(61.9)$ & $0.891(0.442-1.796)$ & 0.89 \\
\hline Absent & $161(79.3)$ & $104(64.6)$ & 1 & \\
\hline \multicolumn{5}{|l|}{ Metastases } \\
\hline Present & $23(11.3)$ & $12(52.2)$ & $0.573(0.239-1.374)$ & 0.31 \\
\hline Absent & $180(88.7)$ & $118(65.6)$ & 1 & \\
\hline \multicolumn{5}{|l|}{ Chemotherapy cycle } \\
\hline$<4$ & $123(60.6)$ & $86(69.9)$ & 1 & 0.04 \\
\hline$\geq 4$ & $80(39.4)$ & $44(55)$ & $0.526(0.293-0.944)$ & \\
\hline
\end{tabular}

Bhattacharyya et al. conducted a cross-sectional descriptive study at the North Bengal Medical College and Hospital from May to June 2013 on 174 cancer patients to find out depression using BEDS. ${ }^{[14]}$ Depression was seen in $55.7 \%$ of patients. Depression was comparatively higher in patients $\geq 50$ years; in males, those belonging to religion other than Hindus; who received higher education; had monthly family income $\geq 5000$ rupees; who were involved in moderate or heavy work; who had blood cancer; who had been receiving chemotherapy for $\geq 6$ months; and those in their $4^{\text {th }}$ or less cycle of chemotherapy.

\section{Conclusions}

Depression is the tip of the iceberg. Among various scales used to measure it, BEDS is an easy and reliable method. In the present study, depression was seen in $64 \%$ of patients, and was found to be significantly associated with both extremes of age, paid treatment, and less number of chemotherapy cycles administered. In spite of such high magnitude, depression often gets unnoticed. Depression should routinely be screened among cancer patients receiving chemotherapy and patients found to have depression need be referred to a psychiatrist for timely management. However, further prospective studies with a large number of patients and inclusion of more variables with focus on its treatment are recommended to address this issue.

\section{Financial support and sponsorship}

Nil.

\section{Conflicts of interest}

There are no conflicts of interest.

\section{References}

1. International Statistical Classification of Diseases and Related Health Problems. $10^{\text {th }}$ Revision (ICD-10)-WHO Version 
for 2016. Mental and behavioural disorders (F00-F99). Mood [affective] disorders (F30-F39). F32 Depressive Episode. Ch. 5. International Statistical Classification of Diseases and Related Health Problems; 2016. Available from: http://www. apps.who.int/classifications/icd10/browse/2016/en\#/F32. [Last accessed on 2017 Sep 25].

2. NCCN Clinical Practice Guidelines in Oncology: Distress Management. Version 2 2017. National Comprehensive Cancer Network; 2017. Available from: https://www.nccn.org/ professionals/physician_gls/f_guidelines.asp\#distress. [Last accessed on 2017 Sep 25].

3. Katon WJ. Epidemiology and treatment of depression in patients with chronic medical illness. Dialogues Clin Neurosci 2011;13:7-23.

4. Lloyd-Williams M, Shiels C, Dowrick C. The development of the brief Edinburgh depression scale (BEDS) to screen for depression in patients with advanced cancer. J Affect Disord 2007;99:259-64.

5. Zielińska-Wieczkowska H, Betłakowski J. Analysis of depression intensification in cancer patients before and during chemotherapy. Wiad Lek 2010;63:46-53.

6. Lloyd-Williams M, Cobb M, O'Connor C, Dunn L, Shiels C. A pilot randomised controlled trial to reduce suffering and emotional distress in patients with advanced cancer. J Affect Disord 2013;148:141-5.

7. Decat CS, de Araujo TC, Stiles J. Distress levels in patients undergoing chemotherapy in Brazil. Psychooncology 2011;20:1130-3
8. Burgess C, Cornelius V, Love S, Graham J, Richards M, Ramirez A, et al. Depression and anxiety in women with early breast cancer: Five year observational cohort study. BMJ 2005;330:702.

9. Pandey M, Sarita GP, Devi N, Thomas BC, Hussain BM, Krishnan $\mathrm{R}$, et al. Distress, anxiety, and depression in cancer patients undergoing chemotherapy. World J Surg Oncol 2006;4:68.

10. Walker J, Holm Hansen C, Martin P, Sawhney A, Thekkumpurath $\mathrm{P}$, Beale $\mathrm{C}$, et al. Prevalence of depression in adults with cancer: A systematic review. Ann Oncol 2013;24:895-900

11. Maneeton B, Maneeton N, Mahathep P. Prevalence of depression and its correlations: A cross-sectional study in Thai cancer patients. Asian Pac J Cancer Prev 2012;13:2039-43.

12. Akechi T, Okuyama T, Uchida $M$, Nakaguchi T, Sugano K, Kubota $\mathrm{Y}$, et al. Clinical indicators of depression among ambulatory cancer patients undergoing chemotherapy. Jpn J Clin Oncol 2012;42:1175-80.

13. Rhondali W, Perceau E, Berthiller J, Saltel P, Trillet-Lenoir V, Tredan $\mathrm{O}$, et al. Frequency of depression among oncology outpatients and association with other symptoms. Support Care Cancer 2012;20:2795-802.

14. Bhattacharyya S, Bhattacherjee S, Mandal T, Das DK. Depression in cancer patients undergoing chemotherapy in a tertiary care hospital of North Bengal, India. Indian J Public Health 2017;61:14-8. 